\title{
Bacterial infections in neonates with congenital heart disease
}

Laura Mihaela Suciu, Manuela Cucerea, Marta Simon

University of Medicine and Pharmacy Tîrgu Mures

Background Despite major advances in prevention, diagnosis, and treatment of bacterial infections, invasive infections remain one of the leading causes of childhood mortality, causing more than 4.5 million childhood deaths each year

Despite antenatal and postnatal screening, bacterial pathogens continue to be an emerging etiology of invasive infections, and thus remains a significant issue especially for neonates with congenital heart disease. The objective of present survey was to determine the frequency of bacterial infections in neonates with congenital heart disease and to evaluate the implication of the bacterial invasion on treatment and outcome.

\section{Methods}

This prospectively data analysis included term and preterm infants with congenital heart disease requiring maintenance of ductus arteriosus (PDA). We studied 66 cases of infants with congenital heart disease receiving PGE1 infusion, hospitalized in one academic, public hospital with tertiary level of Neonatal Intensive Care Unit, during 3 years period from January 2014 to December 2016. A complete blood count, C-reactive protein level and blood culture were obtained within first 24 hours and repeated after 72 hours of life from all infants included in the study.

\section{Results}

Among the entire cohort of 66 neonates with heart disease requiring maintanance of ductus arteriosus, diagnostic of pulmonary flux depending PDA was for 11 ( $16.66 \%$ ), systemic flux depending PDA was for 31 $(46.96 \%)$, and mixing PDA was for 24 $(36.36 \%)$.
Active surveillance has identified in our group $21(31.8 \%)$ infected neonates of which $6(9.1 \%)$ have had positive blood culture within firs 24 hours age, $7(10.6 \%)$ infants have had positive blood culture after 72 hours age and $8(12.1 \%$ ) have had negative blood culture but abnormal blood cell count and elevated C-reactive protein level.

A total of $43(65.2 \%)$ infants were treated with prolonged antibiotics of which $30(70 \%)$ were treated based on abnormal laboratory data. For those infants with positive blood culture, PEG1 infusion doses were higher compare to those with blood culture negative (0.048 micrograms versus 0.032 micrograms, $\mathrm{p}=0.01$ ), and also for those infants who received antibiotics $(0.049$ micrograms versus 0.047 micrograms, $p=0.02$ ).

\section{Conclusions}

Bacterial pathogens impact the management of the neonates with congenital cardiac disease. A large number of infants received antibiotics solely based on abnormally laboratory data.

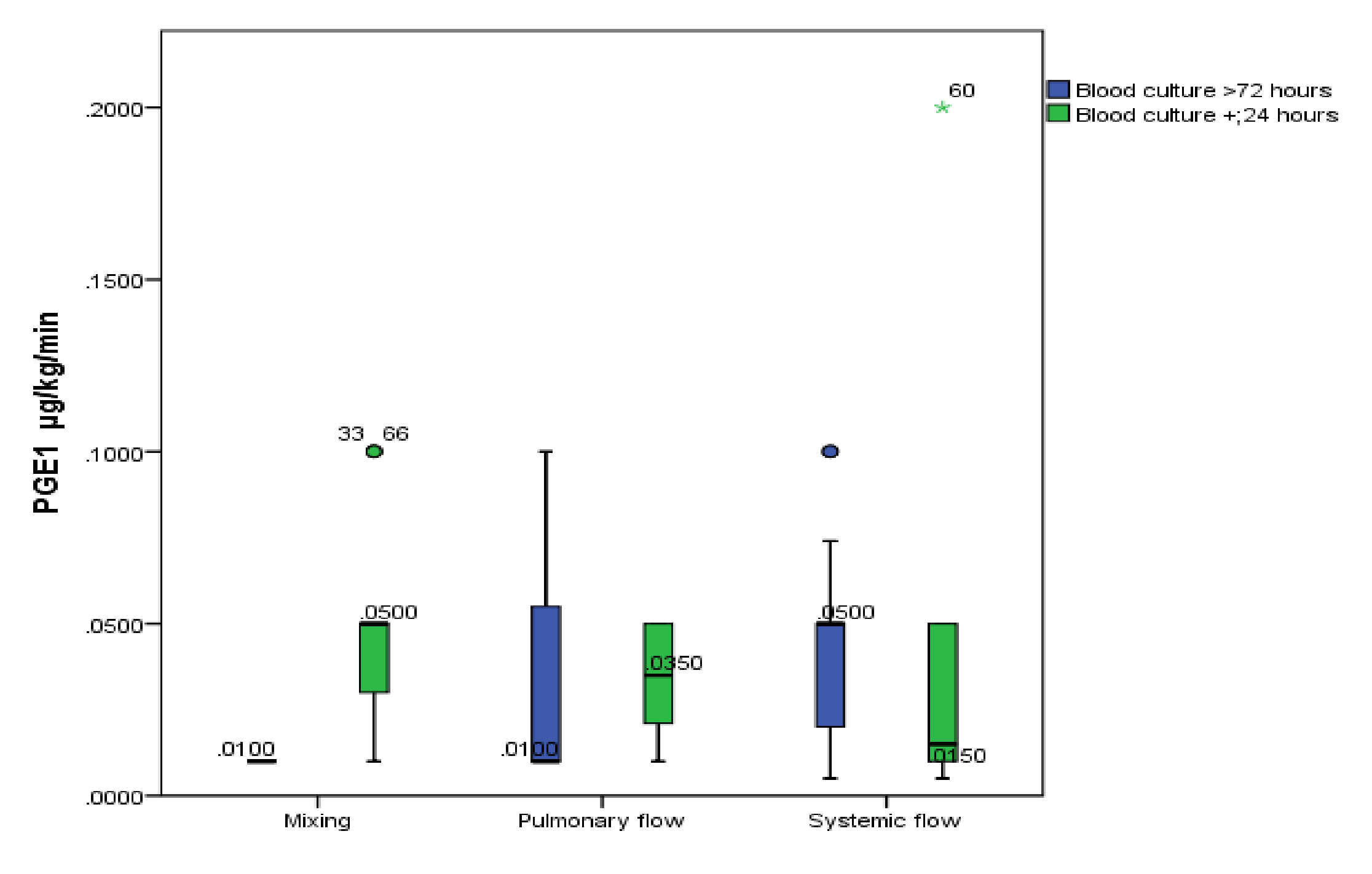

\begin{tabular}{|l|c|c|c|c|}
\hline Variable & $\begin{array}{c}\text { Pulmonary flux } \\
\mathrm{N}=11\end{array}$ & $\begin{array}{c}\text { Systemic flux } \\
\mathrm{N}=31\end{array}$ & $\begin{array}{c}\text { Mixing } \\
\mathrm{N}=24\end{array}$ & $\begin{array}{c}\text { Total } \\
\mathrm{N}=66\end{array}$ \\
\hline Leukocytosis>2x10 & $9(81.8 \%)$ & $24(77.4 \%)$ & $16(66.6 \%)$ & $49(74.24 \%)$ \\
\hline $\begin{array}{l}\text { Blood culture<24 } \\
\text { hours }\end{array}$ & $2(18.18 \%)$ & $2(6.45 \%)$ & $2(8.33 \%)$ & $6(9.09 \%)$ \\
\hline $\begin{array}{l}\text { Blood culture>72 } \\
\text { hours culture>72 }\end{array}$ & $3(27.27 \%)$ & $4(12.9 \%)$ & $7(29.1 \%)$ & $14(21.21 \%)$ \\
\hline $\begin{array}{l}\text { Other } \\
\text { hours }\end{array}$ & & & \\
\hline
\end{tabular}

